\title{
First successful transapical aortic valve implantation after aortic allograft replacement
}

\author{
Michael Schmoeckel, MD, ${ }^{\mathrm{a}}$ Peter Boekstegers, MD, ${ }^{\mathrm{b}}$ Konstantin Nikolaou, MD,${ }^{\mathrm{c}}$ and Bruno Reichart, MD, ${ }^{\mathrm{a}}$ \\ Munich, Germany
}

Aortic allograft reoperation may be difficult, especially when the first procedure was done by miniroot replacement. ${ }^{1}$ We report the case of a 72-year-old patient with increasing dyspnea from severe valvular regurgitation 13 years after aortic allograft replacement and simultaneous coronary artery bypass grafting. A patent left internal thoracic artery to the left anterior descending coronary artery and a venous graft to a diagonal branch were seen on computed tomography and angiography.

Because we had performed 33 transapical valve implantations (Edwards SAPIEN; Edwards Inc, Unterschleissheim, Germany) with a 30 day mortality of $3 \%$, we were confident in the catheter-based implantation of a pericardial valve into this calcified aortic allograft wall.

\section{CLINICAL SUMMARY}

In 1996, the 59-year-old male patient had undergone surgery for aortic stenosis and coronary artery disease. At that time, a 24-mm aortic allograft was implanted as a miniroot, the left internal thoracic artery was anastomosed to the left anterior descending coronary artery, and a saphenous vein graft was connected to the second diagonal branch. Postoperative recovery was uneventful, and the patient did well until the beginning of 2009, when he was seen with increasing dyspnea.

Echocardiography showed severe aortic regurgitation with a slightly dilated left ventricle but preserved performance. The diagnosis was confirmed by aortography and computed tomography, which demonstrated both bypass grafts to be patent (Figure 1) and revealed moderate to severe calcifications within the aortic valve annulus and the wall of the allograft. Annular diameter was measured at $23 \times 25$ $\mathrm{mm}$, with distances from the annulus to the left coronary artery of $12 \mathrm{~mm}$ and to the right coronary artery of $18 \mathrm{~mm}$.

Because of the increased complexity of reoperative aortic valve replacement in the presence of a heavily calcified allograft wall and open bypass grafts, we discussed with the patient the option of a catheter-based transapical aortic valve

From the Departments of Cardiac Surgery, ${ }^{\mathrm{a}}$ Internal Medicine I, ${ }^{\mathrm{b}}$ and Radiology, Klinikum Grosshadern, Ludwig-Maximilians-University, Munich, Germany.

Received for publication May 4, 2009; accepted for publication May 17, 2009; available ahead of print July 27, 2009.

Address for reprints: Michael Schmoeckel, MD, Department of Cardiac Surgery, Klinikum Grosshadern, University of Munich, Marchioninistrasse 15, D-81377

Munich, Germany (E-mail: michael.schmoeckel@med.uni-muenchen.de).

J Thorac Cardiovasc Surg 2009; 138:1016-7

$0022-5223 / \$ 36.00$

Copyright (c) 2009 by The American Association for Thoracic Surgery doi:10.1016/j.jtcvs.2009.05.019 implantation. From our series of open reoperative aortic valve replacements after allograft implantation, we have learned that in time allografts severely calcify within the aortic annulus and wall, whereas the aortic leaflets are usually thin and friable, ${ }^{2}$ features that were verified by computed tomographic scan in this case. Because valve diameter $(<25 \mathrm{~mm})$ and distances to the coronary ostia (both $>9 \mathrm{~mm}$ ) complied with the manufacturer recommendations for transapical valve implantation, we preferred this procedure.

Transapical valve implantation was performed in a hybrid operating room by a team of cardiac surgeons, cardiologists, and anesthesiologists. The chest was entered through an anterolateral minithoracotomy in the 5th intercostal space. The pericardium was incised over the apex, and a pacemaker wire was attached to the left ventricle. After guidewire and sheath positioning, a balloon aortic valvuloplasty was performed to confirm the annular diameter and calculate the necessary balloon filling volume. Then a $26-\mathrm{mm}$ SAPIEN pericardial valve was advanced into the aortic annulus and expanded under rapid pacing. Intraoperative transesophageal echocardiography and fluoroscopy confirmed only minimal aortic regurgitation (Figure 2).

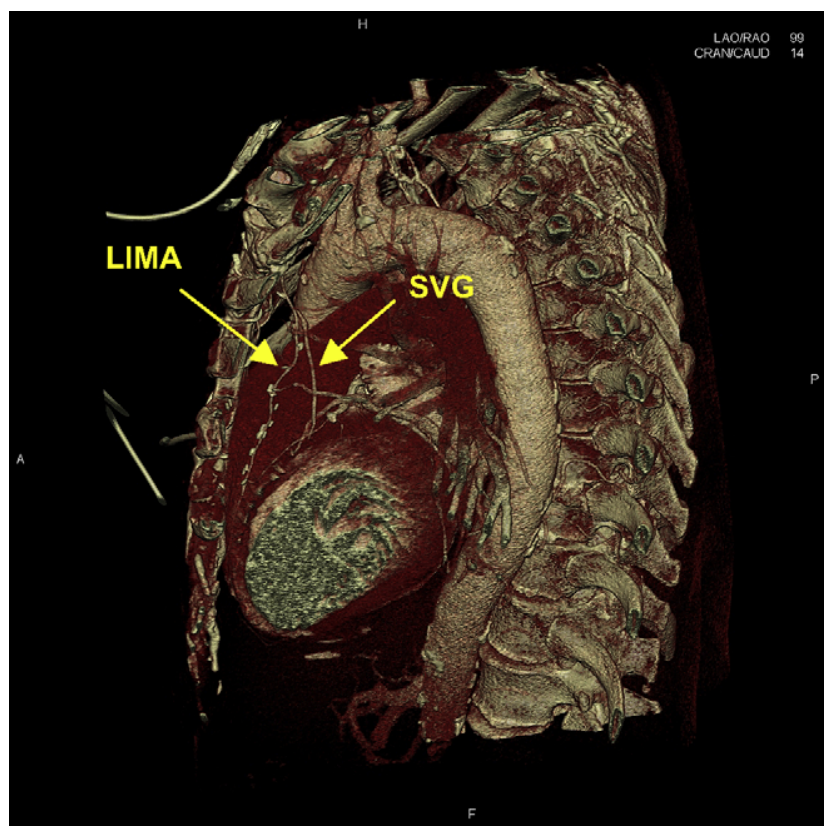

FIGURE 1. Three-dimensional reconstruction of preoperative computed tomographic scan. Arrows indicate open bypass grafts with left internal thoracic artery (LIMA) to left anterior descending coronary artery and saphenous vein graft ( $S V G$ ) to second diagonal branch. 


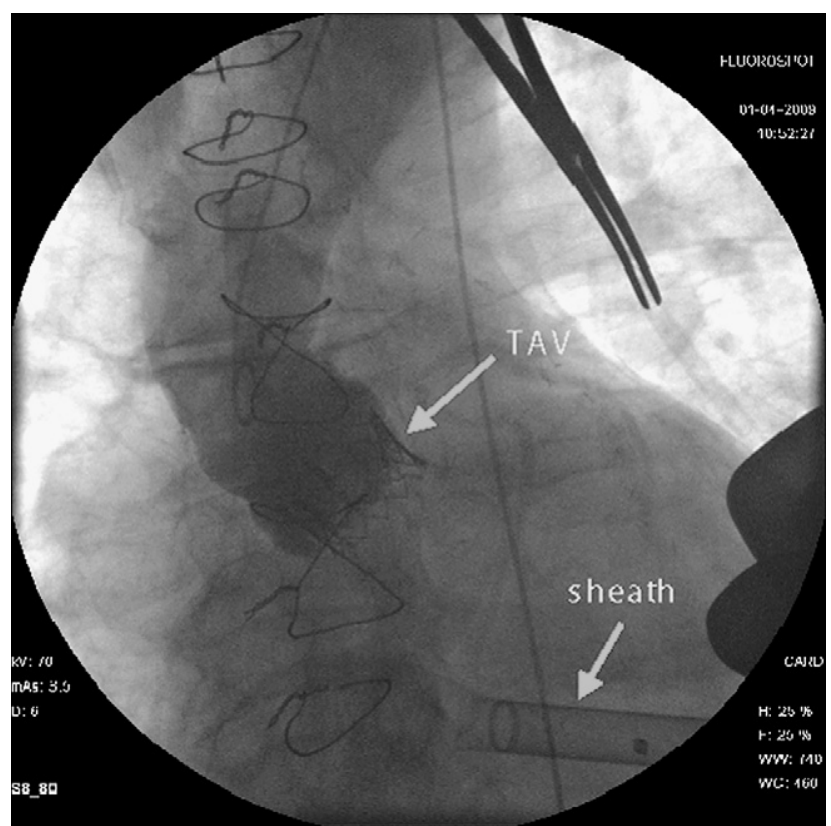

FIGURE 2. Intraoperative aortography after deployment of transapical valve $(T A V)$. After removal of balloon catheter and guidewire through sheath (arrow), only minimal aortic regurgitation was detected.

The patient was transferred to our intensive care unit and extubated in the afternoon of the same day. The postoperative course was uneventful. Transthoracic echocardiography of the prosthesis showed a maximum pressure gradient of $9 \mathrm{~mm} \mathrm{Hg}$ and minimal eccentric aortic regurgitation.

\section{DISCUSSION}

Structural valve deterioration limits the long-term durability of both aortic xenografts and allografts. Ten years after allograft replacement, the reported freedom from tissue degeneration was $80 \%$, and aortic valve reoperation had to be performed in $18 \%$ of the patients. ${ }^{3}$ Technical challenges common to any resternotomy and specific problems related to allograft degeneration put patients at risk. ${ }^{1}$ To avoid injury to patent bypass grafts and débridement of calcified tissue, a minimally invasive procedure appears attractive, especially in the elder age group with multiple comorbidities. Transfemoral and transapical aortic valve implantation routes have been shown to be feasible alternatives for these patients in the presence of aortic stenosis. ${ }^{4}$

An important prerequisite for success of the procedure is sufficient calcification of the aortic annulus to support the stented valve. Isolated aortic regurgitation of the native aortic valve does not necessarily include calcification of the annulus and is therefore not regarded as a typical indication for catheter-based aortic valve implantation. ${ }^{5}$ Structural valve deterioration of allografts, however, in more than half of affected patients leads to aortic regurgitation, which is accompanied by significant calcification of both annulus and aortic wall. ${ }^{3}$ Under these conditions, catheter-based aortic valve implantation is probably as safe as in patients with aortic stenosis.

\section{CONCLUSIONS}

This first reported transapical aortic valve implantation into an aortic allograft provides evidence that this procedure is a feasible option in selected patients suffering from structural valve deterioration after aortic allograft replacement.

\section{References}

1. Nowicki ER, Pettersson GB, Smedira NG, Roselli EE, Blackstone EH, Lytle BW. Aortic allograft valve reoperation: surgical challenges and patient risks. Ann Thorac Surg. 2008;86:761-8.

2. Kilian E, Oberhoffer M, Kaczmarek I, Bauerfeind D, Kreuzer E, Reichart B. Outcome after aortic valve replacement: comparison of homografts with mechanical prostheses. J Heart Valve Dis. 2007; 16:404-9.

3. Hasnat K, Birks EJ, Liddicoat J, Hon JK, Edwards S, Glennon S, et al. Patient outcome and valve performance following a second aortic homograft replacement. Circulation. 1999;100(19 Suppl):II42-7.

4. Ye J, Cheung A, Lichtenstein SV, Altwegg LA, Wong DR, Carere RG, et al. Transapical transcatheter aortic valve implantation: 1-year outcome in 26 patients. J Thorac Cardiovasc Surg. 2009;137:167-73

5. Vahanian A, Alfieri O, Al-Attar N, Antunes M, Bax J, Cormier B, et al. Transcatheter valve implantation for patients with aortic stenosis: a position statement from the European Association of Cardio-Thoracic Surgery (EACTS) and the European Society of Cardiology (ESC), in collaboration with the European Association of Percutaneous Cardiovascular Interventions (EAPCI). Eur Heart J. 2008;29: 1463-70. 